\title{
Preface to the special issue on "Recent Developments and New Directions in Thin-Film Flow"
}

\author{
Stephen K. Wilson • Brian R. Duffy
}

Received: 19 December 2011 / Accepted: 19 January 2012 / Published online: 21 February 2012

(C) Springer Science+Business Media B.V. 2012

Thin films of fluids are of central importance in numerous industrial, biomedical, geophysical and domestic applications, and display a rich and varied range of behaviours, including pattern formation, dewetting, rupture and finite-time blow up. As well as being of great interest in their own right, thin-film flows provide a "test bed" for research into a variety of challenging nonlinear problems in engineering, physics, chemistry, biology, and mathematics. As a consequence, research by a wide range of scientists, using a variety of analytical, numerical and experimental techniques on many different aspects of thin-film flow, has grown significantly in recent years, as novel applications have continued to appear and increasingly sophisticated theoretical and experimental techniques have been developed.

This special issue of the Journal of Engineering Mathematics on "Recent Developments and New Directions in Thin-Film Flow" arises from European Mechanics Society Colloquium 497 (“EUROMECH 497”) with the same title held at the International Centre for Mathematical Sciences (ICMS) in Edinburgh on 6th to 9th July 2009. The aim of this Colloquium was to bring together international experts in thin-film flow from across several different traditional academic disciplines, including mathematics, engineering, physics and chemistry, to report on their latest discoveries and to foster new interdisciplinary collaborations. The Colloquium was a natural continuation of an informal series of meetings on thin-film flow which have taken place in recent years, including the ICMS workshop "The Dynamics of Thin Films" (Edinburgh, 1999), the Banff International Research Station (BIRS) workshop "Nonlinear Dynamics of Thin Films and Fluid Interfaces" (Banff, 2003) and EUROMECH 490 "Dynamics and Stability of Thin Liquid Films and Slender Jets" (London, 2007), and has already been followed by the BIRS workshop "Small Scale Hydrodynamics: Microfluidics and Thin Films" (Banff, 2010). Similarly, this volume adds to a growing number of special issues of journals on thin-film flow, including [1,2] and [3].

EUROMECH 497 was organised by Professor Stephen Wilson (Colloquium Chair) and Dr Brian Duffy from the University of Strathclyde in Glasgow together with Professor George "Bud" Homsy from the University of California, Santa Barbara (now at the University of British Columbia). In addition to the financial support provided by EUROMECH, the financial and organisational backing of the ICMS provided significant funding from the UK Engineering and Physical Sciences Research Council (EPSRC) and the London Mathematical Society (LMS). The scientific sessions took place in the historic Royal Society of Edinburgh building in central Edinburgh, and the welcome reception was held in the nearby house in which James Clark Maxwell was born 1831 (which was the home of the ICMS at the time of the meeting). The mix of participants was impressively international, with 7 from

S. K. Wilson $(\varangle) \cdot$ B. R. Duffy

Department of Mathematics and Statistics, University of Strathclyde, Glasgow, UK

e-mail: s.k.wilson@strath.ac.uk 
France, 6 from Germany, 4 from the USA, 2 from the Netherlands and one from each of Belgium, Ireland, Israel and India, in addition to the 26 from the United Kingdom. A full list of participants together with the titles and abstracts of all the talks presented, plus some photographs taken during the Colloquium, can be found on the ICMS webpages at www.icms.org.uk/workshops/thinfilms. Scientifically the Colloquium was very successful, with a full programme of 40 formal scientific presentations and plenty of opportunities for informal meetings and discussions. The smooth running of the Colloquium was due to the tireless efforts of the ICMS staff involved, namely Johanna Kytöharju, Irene Moore and Helen Bridle, all three of whom were immensely patient and efficient throughout. Indeed, one participant went on record to say "I found the organisation outstandingly efficient thanks to the enthusiasm, professionalism and helpfulness of the ICMS staff" and added "Academically, the talks were of consistently high quality, and the friendly and convivial atmosphere (augmented by generously subsidised social activities) made it one of the most enjoyable meetings of my career", while another simply described the Colloquium as "...the best and the most interesting scientific meeting I have ever seen!"

Nevertheless, this special issue is not simply a volume of proceedings of EUROMECH 497. Only a fraction of the participants are represented here, and not all of the work reported here was presented at the Colloquium. Rather this special issue aims to capture the spirit of the Colloquium with a collection of eight high-quality research papers by leading researchers on various aspects of thin-film flow. However, it is hoped that this special issue also provides a fitting permanent record of four very enjoyable days of stimulating scientific interaction which took place in Edinburgh in the summer of 2009. Specifically, in the first paper Savva and Kalliadasis consider the influence of gravity on the spreading of a two-dimensional droplet over a spatially heterogeneous substrate. In the next three papers Todorova, Thiele and Pismen, Ajaev et al., and Gambaryan-Roisman address three different problems involving the evaporation of a thin droplet or film, namely the steady and the unsteady evaporation of a two-dimensional droplet, the fingering instability of the leading edge of an evaporating film flowing down an inclined substrate, and the Marangoni-induced deformation of an evaporating two-dimensional film on a substrate with spatially periodic thermal properties. In the next paper, Yatim, Duffy and Wilson derive and analyse similarity solutions for the unsteady shear-stress-driven flow of a slender rivulet and around a slender dry patch. In the final three papers, Ward and King, Taroni et al., and Braun et al. consider three very different physical contexts in which thin films of fluid play a key role, namely biofilm growth, screen printing, and the tear film on the human cornea.

\section{References}

1. Wilson SK (ed) (2001) Special issue on “The Dynamics of Thin Fluid Films”. Euro J Appl Math 12(3):193-431

2. Crowdy DG, Lawrence CJ, Wilson SK (eds) (2004) Special issue on "The Dynamics of Thin Liquid Films". J Eng Math 50(23):95-341

3. Behringer RP, Shearer M (eds) (2005) Special issue on "Nonlinear Dynamics of Thin Films and Fluid Interfaces, Workshop on Nonlinear Dynamics of Thin Films and Fluid Interfaces". Phys D 209(1-4):1-266 